\title{
Why Do We Let Psychopaths Abuse Us In Plain Sight?
}

\author{
Leah Savion* and Nicholas Riina \\ Department of Philosophy, Indiana University, USA
}

*Corresponding author: Leah Savion, Department of Philosophy, Indiana University, USA.

To Cite This Article: Leah Savion. Why Do We Let Psychopaths Abuse Us In Plain Sight?. Am J Biomed Sci \& Res. 2019 - 5(5). AJBSR.MS.ID.000954. DOI: 10.34297/AJBSR.2019.05.000954.

Received: 制September 18, 2019; Published: 眥 October 16, 2019

\section{Opinion}

What do Hitler, Madoff, Ted Bundy, and Stalin have in common? They are all easily identified as psychopaths by the lay person. We notice extremes like the dark triad (psychopathy, narcissism, Machiavellianism), displayed by a cynical, calculating, merciless leaders, but we are oblivious otherwise. What we fail to realize is that most psychopaths are not either CEOs or behind bars. The culprit for the "misunderstanding" of psychopathy, mis-diagnosis, and ubiquitous ignorance about the lurking danger of these people is often viewed as the professional definitions. The criteria for psychopathy are infested with ambiguity (confusion with kin personality disorders such as Borderline Personality Disorder, Narcissism, or Anti-Social Personality Disorder), vagueness (dimensional identification), and inconclusive scientific research of the genetics and the neurology underpinning of lack of mpathy, manipulation, and ruthlessness. We believe that the blame rests primarily in the recipient's end of the phenomenon: important cognitive mechanisms play a significant role in our inability to recognize the charming cult leader, the lies and gaslighting of our abusive spouse, and our tremendous need to please the psychopath's superiority, posing impossible standards on us.

The confinements of an opinion paper limit our suggestions to three main areas: common human desires, dispositions, and the cognitive heuristics we employ regularly. Our basic (first order) desires include money, food, sex, and love. Second order desires - desires about what to desire -- encompass all of the basic ones but are less available to introspection. They are directed by needs such as social acceptance, success in life defined contextually, and constructing an "ideal" environment to live in (democracy, literacy, spirituality, fairness, and helping the less fortunate). These desires create a grainy perception of the charismatic psychopath, blinding us to being manipulated, constantly lied to, used, and even physically or emotionally abused. Our common tendencies and dispositions for overly simple, black and white explanations, for having a sense of control over our immediate environment, and for erecting and maintaining an "above average" ego contribute to our blind spot regarding the psychopath: we brush off clear manipulation under the guise of "I'll never fall for it", we excuse his lack of remorse and empathy as "ambition and strength needed for coping in our savage world", and ignore aggressive violations of social norms by dressing them up as a "manic episode", a "temper tantrum" or "a mere glimpse of narcissism". Our cognitive machinery is run by "quick and dirty" rules of thumb, called "heuristics". These shortcuts are inevitable and necessary for survival, but they exact a price on our mental capacities: the "Ingroup" heuristic creates a tunnel vision about negative attributes of the people we have adapted into our inner circle, allowing the psychopath to hide and operate in plain sight. The "Framing Effect" can be utilized ingeniously by the psychopath who distorts the perception of actions that support their goals at our expense.

The "Anchoring heuristic" helps our need for cognitive efficiency by generating beliefs and impressions based on initial presentations, while the confirmation bias prevents further investigation. The psychopath impresses us with glib charm and advanced social skills, so we rarely test our first impression against later evidence to the contrary. We look with disbelief, even disgust, at people who let themselves be financially scammed, drink the notorious Kool-Aid, or tolerate an abusive spouse for years on end, while we think "this would never have happened to me". It does: we are constantly at risk of significant harm and manipulation from the charming psychopath next door. His grandiose superiority, his consistent impatience with the "lowly" people, the selfpitying aggrieved disposition, and the incessant lying - these trademarks of the psychopath play straight into our desires, our dispositions, and our cognitive heuristics, turning us sheepish, eager to please, gullible, ignorant... victims. So, let's not blame the 
DMS-V for reducing psychopathy to a vague "Anti-Social Personality Disorder", or the psychiatrists who cannot distinguish "Borderline Personality Disorder" from anxiety. Rather, let's activate our meager introspection acumen to find the cognitive sources of blindness to the prevailing psychopathic population, and our inability to protect ourselves from their malignancy. That knowledge is the necessary first step for "taking shelter", reducing the harmful effects, and call the psychopaths out naked on the social stage. 